\title{
The Impact of Physiology Prerequisites on Future Anatomy and Physiology Courses
}

\author{
Justin F. Shaffer ${ }^{*}$, Samuel E. Schriner ${ }^{2}$, Catherine Loudon ${ }^{3}$, Samantha J. Dacanay ${ }^{4}$, Usman Alam4, Jennifer V. Dang ${ }^{4}$, \\ Nancy Aguilar-Roca ${ }^{3}$, Pavan Kadandale ${ }^{4}$, Brian K. Sato ${ }^{4 *}$ \\ 'Department of Chemical and Biological Engineering, Colorado School of Mines, Golden, CO 80401 \\ ${ }^{2}$ Department of Pharmaceutical Sciences, University of California Irvine \\ ${ }^{3}$ Department of Ecology and Evolution, University of California Irvine \\ ${ }^{4}$ Department of Molecular Biology and Biochemistry, 2238 McGaugh Hall MC3900, University of California Irvine, CA 92697 \\ *Corresponding authors: jshaffer@mines.edu, bsato@uci.edu
}

\begin{abstract}
Universities use prerequisites to regulate the path of students through a program or major. However, the impact of prerequisites on follow-up courses in anatomy and physiology is not well understood. If success in follow-up courses depends on completion of prerequisite courses, then students should earn higher grades on exam questions that assess prerequisite knowledge. To test this hypothesis, we investigated the potential impact of a required prerequisite human physiology lecture course on a followup human physiology laboratory course and a follow-up molecular pharmacology course. We also investigated the potential impact of a recommended prerequisite human physiology laboratory course on a follow-up human anatomy course. We assessed student exam performance in the follow-up courses based on their familiarity with the material from the required prerequisite course or the recommended prerequisite course. Our results were mixed and demonstrated limited performance gains in the follow-up courses despite overlap of material among the courses. These results suggest that prerequisite courses may not have a significant impact on the outcome of future related courses and that individual academic programs should evaluate the effectiveness of prerequisite courses in a local context. http://doi.org/10.21692/haps.2018.025
\end{abstract}

Key words: physiology, undergraduate, curriculum, familiarity, prerequisites

\section{Introduction}

Prerequisite courses are widespread in Science, Engineering, Technology, and Math (STEM) majors at colleges and universities and students must often successfully complete one or more prerequisite courses in order to advance to the next course in a series. Prerequisite courses may exist for a variety of reasons, including content-specific reasons (e.g. the next course in a series directly builds on the material or skills students learn in the prerequisite course), other academic reasons (e.g. students should not take a certain course until they have reached upper-division standing even if the course content does not directly build on the material from the prerequisite course) or logistical reasons (e.g. future course enrollment can be predicted based on enrollment in the prerequisite). Despite the specific reason for a particular prerequisite course, for thorough programmatic assessment it is important to evaluate whether prerequisite courses directly impact student success in follow-up courses.

In the biological sciences, human physiology courses are often paired with human anatomy courses either by requiring that one be taken before the other, or by combining human anatomy and physiology in an Anatomy and Physiology I and Anatomy and Physiology II series. Additionally, human physiology lecture courses may serve as prerequisites for more advanced physiology lecture courses or physiology laboratory courses. In theory, the linked prerequisite and follow-up courses should be designed in a manner to allow students to scaffold their knowledge, guided by the core set of physiology concepts established by Michael and McFarland (2011).

To a minimal degree, the impact of prerequisite courses and prior student knowledge on later success has been examined in the context of physiology education. While the number of past science courses taken and university grade point average (GPA) have been found to positively correlate with passing grades in physiology courses (McCleary et al. 1999), success is also impacted by faulty mental models or misconceptions, derived from personal experience with the subject matter, or related to prior classroom instruction (Michael 1998). For example, student misconceptions in cardiovascular physiology (Michael 1998) and respiratory physiology (Michael 1998, Michael et al. 1999) have been described, which may impact student success in subsequent physiology courses. In an attempt to address this issue, Modell et al. (2000) used various laboratory protocols in an attempt to "repair" faulty mental models that students hold about how tidal volume responds to changes in minute ventilation (Michael 1998, Michael et al. 1999). They found that students "corrected" their misconceptions to the greatest extent when following laboratory protocols that required them to not only predict their experimental results but to verbally explain them to their instructor before attempting the experiment. 
Regardless of where misconceptions came from, we assume that students apply the knowledge gained from prior physiology courses to subsequent ones, building on their existing knowledge. However, in a specific instance assessing student understanding of the cardiovascular system, Richardson (2000) found no impact of a recommended basiclevel physiology course on performance on cardiovascular items in a subsequent upper-division physiology course. Additionally, Rovick et al. (1999) found that physiology instructors were poor judges of students' incoming knowledge (whether they had taken a physiology prerequisite course or not) and specifically overestimated students' ability to apply whatever prior knowledge they had. Taken together, these studies suggest that prerequisites course and misconceptions may have negative effects on future performance in physiology courses and that more work is needed to understand how these factors may influence student success.

Prerequisites can be either required or recommended for student enrollment in a subsequence course. If the prerequisite course is suggested but not required, comparing the performance of students who have or have not completed the prerequisite may assess its impact on the follow-up course. Indeed, several studies have explored this type of analysis. In a study of first-year medical students, Forester et al. (2002) found that students who had completed a gross anatomy course during their undergraduate program earned significantly higher grades in a gross anatomy course at the medical school level. McRae et al. (2010) found a similar result in that student grades in an undergraduate organic chemistry course were significantly correlated with grades earned in a chiropractic biochemistry course. While these studies showed positive connections between prerequisites and follow-up courses this may be due to the fact that these studies examined graduate students, a highly motivated population.

Other studies have reported a lack of correlation. Wright et al. (2009) examined performance in a biochemistry course and found that students performed equally well whether they had completed an organic chemistry prerequisite or not. Canaday and Lancaster (1985) found that there was no impact of undergraduate courses in biochemistry, vertebrate anatomy, histology, or embryology on the GPA of first-year medical students, courses that would presumably provide students with an advantage in medical school. Lastly, Steele and Barnhill (1982) found that an undergraduate genetics course had no impact on student performance in a medical school genetics course. Given the variability in these results, it is possible that prerequisites may (or may not) be important for discipline-specific reasons or for specific student populations.

On the other hand, if the prerequisite course is required before enrolling in the follow-up course, an alternative assessment approach must be taken due to the lack of a control group that has not completed the prerequisite. One method to examine the impact of prerequisites in this scenario is by assessing student performance on exam questions in the follow-up course that are based on the level of familiarity one has with the tested content from the prerequisite course (Shaffer et al. 2016, Sato et al. 2017). In this analysis, exam questions are coded (by instructors, students, or lecture slide analysis) as "very familiar" if the topic was previously covered extensively in the prerequisite, "familiar" if the topic was briefly introduced in the prerequisite course, and "not familiar" if the topic was not taught at all in the prerequisite course. Shaffer et al. (2016) examined the impact of a genetics prerequisite on performance in a molecular biology course and a human physiology prerequisite on performance in a human anatomy course. This study (Shaffer et al. 2016) demonstrated limited differences on performance among questions of varying familiarity, suggesting that students did not necessarily utilize or need their prerequisite knowledge in follow-up courses. Sato et al. (2017) found similar results using the familiarity analysis for a microbiology lecture course that served as a recommended prerequisite for a microbiology laboratory course.

As human physiology courses are often tightly coupled with advanced physiology lecture courses, physiology laboratory courses, or human anatomy courses, we sought to determine the impact of physiology courses on related subsequent courses. Since prior studies have shown little or no impact of prerequisites on student success on specific topics taught in physiology courses (Richardson 2000) it is important to know if this is also the case on a course wide basis. Specifically, this study addresses the following research questions in the context of a large research-intensive university:

1. Does content familiarity from a required undergraduate prerequisite human physiology course impact exam performance in a follow-up physiology laboratory course or a molecular pharmacology course?

2. Does enrollment in a recommended undergraduate physiology laboratory course predict higher exam scores in a follow-up human anatomy lecture course?

\section{Materials and Methods}

\section{Study Context}

This study was conducted at a large, PhD-granting research university in the western United States. Data were collected from two sections (Winter 2016 ( $\mathrm{n}=218$ students) and Spring $2016(n=150))$ of an upper division Biological Sciences physiology laboratory course (Bio PL, taught by author NAR), one section (Winter 2016, $\mathrm{n}=139$ ) of an upper division molecular pharmacology (MP, taught by author SES) course, and three sections (Spring 2015, Winter 2016, and Spring 2016, total $n=377$ students) of an upper division human anatomy course (HA, taught by author JFS). These courses were associated with prerequisites that were examined in this study, specifically with the particular pathways illustrated in Figure 1 and course descriptive information in Table 1. 
RQ1

\begin{tabular}{|c|c|c|}
\hline $\begin{array}{c}\text { Bio Sci } \\
\text { Human Physiology } \\
\text { Lecture }\end{array}$ & $\stackrel{n=368}{\longrightarrow}$ & $\begin{array}{c}\text { Bio Sci } \\
\text { Physiology Lab } \\
\text { (Bio PL) }\end{array}$ \\
\hline & RQ1 & \\
\hline $\begin{array}{c}\text { Pharm Sci } \\
\text { Human Physiology } \\
\text { Lecture }\end{array}$ & $\stackrel{n=139}{\longrightarrow}$ & $\begin{array}{c}\text { Molecular } \\
\text { Pharmacology } \\
\text { Lecture } \\
\text { (MP) }\end{array}$ \\
\hline
\end{tabular}

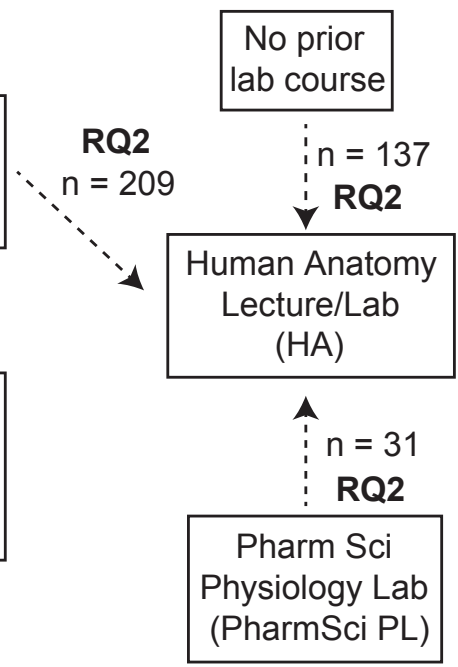

Figure 1. Sequence of study courses. Performance in Biological Sciences Physiology Lab (Bio PL), Molecular Pharmacology (MP), and Human Anatomy (HA) courses were examined in the context of their respective prerequisites. An additional course, a pharmaceutical sciences physiology lab (PharmSci PL) served as a prerequisite for $H A$. Solid arrows indicate that the course to the left is a required prerequisite while a dotted arrow indicates that the course to the left is a recommended prerequisite.

Table 1. Study Courses

\begin{tabular}{|c|c|c|}
\hline Course & Course Description & Course Assessments \\
\hline $\begin{array}{l}\text { Bio Sci Human } \\
\text { Physiology } \\
\text { Lecture }\end{array}$ & $\begin{array}{l}\text { How a human body works, focusing interactions between the } \\
\text { digestive, muscular, endocrine, respiratory, cardiovascular, efferent } \\
\text { nervous, and reproductive systems. }\end{array}$ & $\begin{array}{l}\text { Weekly online quizzes, weekly } \\
\text { homework sets, in-class "clicker" } \\
\text { activities, } 2 \text { midterms, final exam }\end{array}$ \\
\hline $\begin{array}{l}\text { Pharm Sci } \\
\text { Human } \\
\text { Physiology } \\
\text { Lecture }\end{array}$ & Function of the human body covering all major organ systems & 3 midterms, final exam \\
\hline $\begin{array}{l}\text { Bio } \\
\text { Sci Physiology } \\
\text { Lab }\end{array}$ & $\begin{array}{l}\text { Laboratory with a focus on the whole organism and its organ } \\
\text { systems. Examples of structure-function relationships are drawn } \\
\text { from both animal and human physiology. This courses also fulfills } \\
\text { an upper-division writing requirement. }\end{array}$ & $\begin{array}{l}\text { Weekly short writing assignments, } \\
1 \text { major lab report, } 3 \text { midterms, final } \\
\text { exam }\end{array}$ \\
\hline $\begin{array}{l}\text { Molecular } \\
\text { Pharmacology } \\
\text { Lecture }\end{array}$ & $\begin{array}{l}\text { Basic pharmacodynamics and pharmacokinetics, and drug } \\
\text { mechanisms for cardiovascular disease and diabetes }\end{array}$ & 3 midterms, final exam \\
\hline $\begin{array}{l}\text { Human Anatomy } \\
\text { Lecture \& Lab }\end{array}$ & $\begin{array}{l}\text { A broad overview of the anatomy of the organ systems of the } \\
\text { human body focusing on structure-function relationships }\end{array}$ & $\begin{array}{l}\text { Online pre-class assignments, weekly } \\
\text { review quizzes, in-class "clicker" } \\
\text { activities, } 3 \text { lecture midterms, lecture } \\
\text { final exam, } 2 \text { laboratory practical } \\
\text { exams }\end{array}$ \\
\hline
\end{tabular}

All of these courses are taken by third through fifth year students (primarily fourth year students), except for the Spring sections of HA in which approximately one-third of the enrollment is made up of second-year nursing science students. Fifth year students include transfer students or students taking extra time to graduate due to making up courses, double majoring, etc. The majority of students enrolled in the Bio PL and HA sections were Biological Sciences majors, while the majority of students in MP were Pharmaceutical Sciences majors. Enrollment in Bio PL and HA required successful completion (a grade of $C$ or better) of an upper division physiology lecture course taught within the School of Biological Sciences. Additionally, students enrolled in HA may or may not have successfully completed Bio PL prior to enrolling in HA. Enrollment in MP required successful completion (a grade of $\mathrm{C}$ or better) of a distinct upper division physiology lecture course taught within the Department of Pharmaceutical Sciences.

\section{Data Collected}

Data from Bio PL and MP, in the form of performance on individual exam questions, were collected. This included 51 questions from the Winter Bio PL exams, 57 questions from the Spring Bio PL exams, and 60 questions from the MP exams. The authors evaluated each question in terms of the Core Concepts in Physiology (12) in order to determine what physiology concepts the exams assessed. The majority of questions in the Bio PL course addressed Core Concepts 
7 (Structure/Function) and 8 (Scientific Reasoning), whereas the majority of questions in the MP course addressed Core Concepts 1 (Homeostasis) and 2 (Cell Membrane). The questions in the Bio PL course covered cardiovascular physiology, respiratory physiology, muscle contraction, exercise physiology, and metabolism, while the questions in the MP course covered cell signaling, metabolism, and cardiovascular physiology. Final course grades in HA were evaluated which included performance on four lecture exams and two laboratory practical exams.

The Institutional Review Board of the University of California, Irvine approved this study. (HS\# 2015-1455 and HS\# 20139959).

\section{Familiarity Designation}

Exam question familiarity based on the material presented in the prerequisite human physiology courses for Bio PL and MP was assigned as previously described (Shaffer et al. 2016, Sato et al. 2017). Briefly, the instructors for the Biological Sciences and Pharmaceutical Sciences human physiology courses examined the Bio PL and MP exam questions and rated each as very familiar (VF), familiar (F), or not familiar (NF) based on the material taught in the physiology courses. A "VF" question is one that could have been answered by a student who had enrolled in the human physiology prerequisite but had yet to be exposed to the Bio PL or MP course. An "F" question covered material taught in the prerequisite course, but not in enough detail to answer the question, and a "NF" question covered a topic not discussed in the prerequisite. In addition to instructor-designated familiarity, members of the research team (SJD, JVD, UA) characterized familiarity utilizing lecture slides from the prerequisite courses. Consensus was reached according to previously described methods (Welsh 2012, Heiner et al. 2014). Each team member characterized exam familiarity independently. This was followed by a group discussion to identify consensus. For areas where there was significant disagreement among team members, discussion continued until consensus was reached. A high level of agreement among the study team was reached, with two of the three authors agreeing $88 \%$ of the time for the winter Bio PL exam questions, 93\% of the time for the spring Bio PL exam questions, $93 \%$ of the time for the spring Bio PL exam questions, and $98 \%$ of the time for MP exam question designation.

In addition, the Bloom's level of each question (Bloom et al. 1956) was determined by members of the research team (JS, NA, PK). Each individual rated the questions independently. Two of the three study authors agreed $81 \%$ of the time for the winter Bio PL exam questions, $83 \%$ of the time for the spring Bio PL exam questions, and $90 \%$ of the time for MP exam question designation. Question familiarity and Bloom's level designations can be seen in Table 2.

Table 2. Exam question descriptive statistics

\begin{tabular}{|c|c|c|c|c|c|}
\hline Course & Familiarity & $\begin{array}{l}\text { \# of Questions } \\
\text { based on Instructor }\end{array}$ & $\begin{array}{c}\text { Average Bloom's } \\
\text { level }\end{array}$ & $\begin{array}{c}\text { \# of Questions } \\
\text { based on Lecture } \\
\text { Slides }\end{array}$ & Average Bloom's level \\
\hline \multirow[t]{3}{*}{ Winter PL } & VF & 10 & 2.9 & 6 & 3.0 \\
\hline & $\mathrm{F}$ & 13 & 2.5 & 17 & 2.8 \\
\hline & NF & 28 & 2.6 & 28 & 2.5 \\
\hline \multirow[t]{3}{*}{ Spring PL } & VF & 17 & 2.8 & 9 & 2.8 \\
\hline & $\mathrm{F}$ & 17 & 2.9 & 15 & 3.0 \\
\hline & $\mathrm{NF}$ & 23 & 2.7 & 33 & 2.7 \\
\hline \multirow[t]{3}{*}{ MP } & VF & 11 & 1.2 & 6 & 3.0 \\
\hline & $\mathrm{F}$ & 12 & 1.4 & 11 & 1.8 \\
\hline & NF & 37 & 2.0 & 43 & 1.5 \\
\hline
\end{tabular}

Exam questions from each course were categorized based on familiarity, according to either instructor of the prerequisite course or by an independent team who viewed the course lecture slides, as described in the methods. The number of questions in each familiarity bin are shown above, as are the average Bloom's level of the questions in each bin. 


\section{Data Analysis}

The impact of the human physiology prerequisite courses on Bio PL and MP performance was determined as previously described (Shaffer et al. 2016, Sato et al. 2017). Briefly, Bio PL and MP exam questions were segregated in two different ways, one based on instructor-designated familiarity and one based on the lecture slide designated familiarity. A multiple regression analysis was then run in which performance on an exam question was examined using both familiarity and Bloom's level as variables. After running these models, it was determined that Bloom's level did not significantly impact performance. Thus, rather than utilize multiple regression analysis, we ran an ANOVA for each course to determine whether question familiarity impacted performance as well as individual t-tests with Tukey contrasts to determine whether performance differed in pairwise comparisons between familiarity groups (VF versus F, F versus NF, VF versus NF).

To highlight the similarity, or lack thereof, between exam question familiarity designations by instructor and lecture slide, we compared designations for each question. If the question designation was identical between the two methods, the level of agreement was characterized as "agree". It was labeled as "slightly agree" if the question designation varied by one level (i.e. very familiar by lecture slide but familiar by instructor). And it was labeled as "disagree" if the designation varied by two levels (i.e. very familiar by lecture slide but not familiar by instructor).

To determine the possible impact of a recommended human physiology laboratory course on student performance in $\mathrm{HA}$, final grades in $\mathrm{HA}$ were compared for students who had completed a physiology laboratory course offered by the School of Biological Sciences (Bio PL; $n=209$ ), a physiology laboratory course offered by the Department of Pharmaceutical Sciences (PharmSci PL; $n=31$ ) or lack of either course $(n=137)$. Multiple linear regression models were developed using final grades (as a percentage out of 100) as the response variable and prior laboratory course completion (a three-level factor variable) and overall GPA as explanatory variables.

\section{Results}

Impact of content familiarity on PL and MP exam performance. We examined exam question performance in the Bio PL and MP courses in the context of how familiar the tested concepts were from their respective prerequisite physiology courses. If the material taught in the prerequisite course was important for future success, we predicted that student performance would be highest on Bio PL and MP VF questions, then F questions, and finally NF questions. When analyzing exam performance in the winter and spring Bio PL courses, we found variable results in regard to the impact of familiarity on performance. For the winter quarter exam data, instructordesignated familiarity had no impact on exam performance, while students actually performed slightly better on NF exam questions when familiarity was designated by lecture slides
(Figure 2A, 2B). For the spring exam data, students earned significantly higher exam scores on VF questions designated by instructor, but there was no impact on familiarity as designated by lecture slides. Data from the MP course exams similarly demonstrated that concept familiarity does not have an obvious impact on performance, as there was no significant difference in exam score using either instructor or lecture slide to designate familiarity (Figure 3A, 3B).
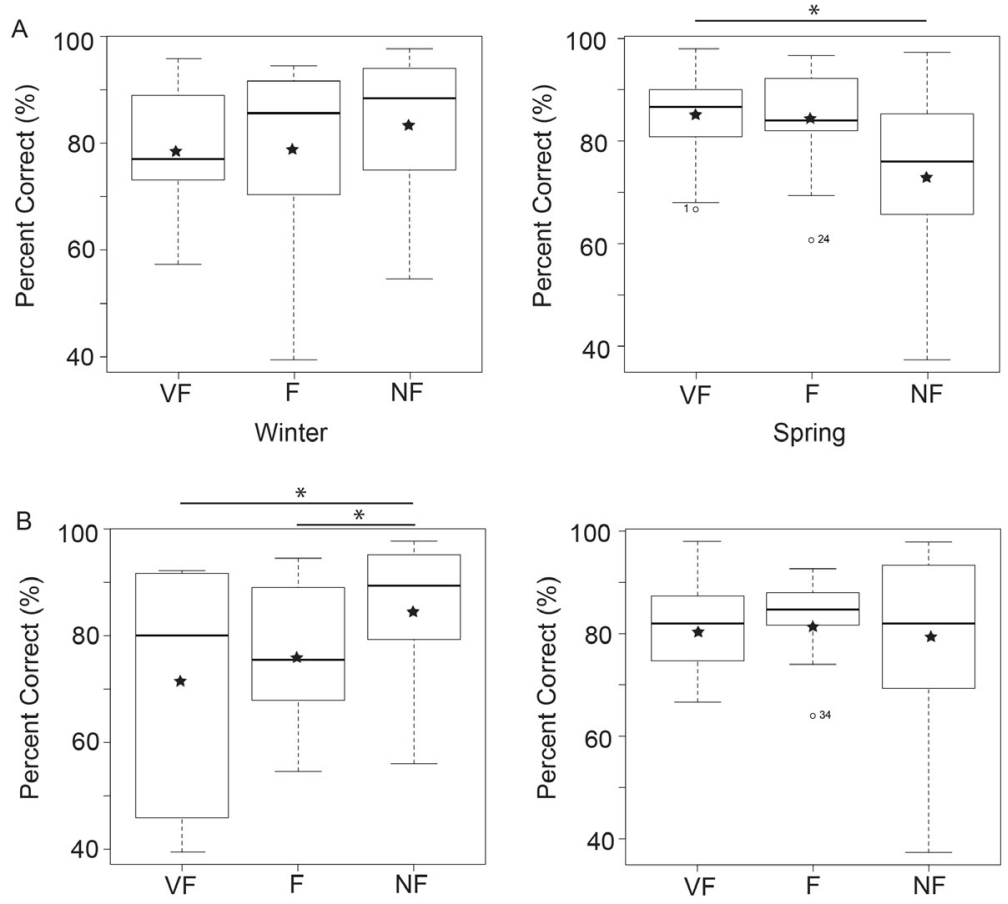

Figure 2. Impact of prerequisite familiarity on Bio PL course exam performance. Exam questions from the winter and spring Bio PL courses were characterized based on familiarity as designated by either $(A)$ the prerequisite course instructor or $(B)$ the prerequisite course lecture slides. Box plots present the distribution of scores for questions of the indicated familiarity level. The stars indicate the mean score for that particular group of questions. VF = very familiar, $F=$ familiar, $N F=$ not familiar, ${ }^{*} p=0.04$
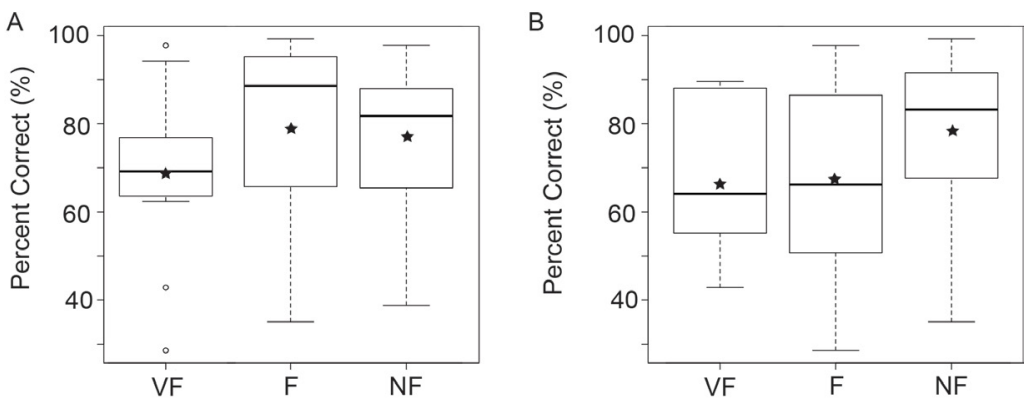

Figure 3. Impact of prerequisite familiarity on MP course exam performance. Exam questions from the MP course were characterized based on familiarity according to either $(A)$ the prerequisite course instructor or $(B)$ the prerequisite course lecture slides. Box plots present the distribution of scores for questions of the indicated familiarity level. The stars indicate the mean score for that particular group of questions. 
We were curious as to whether the differences in prerequisite impact on the winter and spring quarters of Bio PL were due to different student demographics for those enrolled in the two quarters. We compared a variety of student characteristics by Chi-squared test and found that students did not differ by gender $(p=0.33)$, percentage of underrepresented minorities status $(p=0.22)$, low-income status $(p=0.48)$, first generation status $(p=0.87)$, and Math SAT score $(p=0.28$ by ANOVA).

As the impact of concept familiarity on performance was variable depending on the method utilized to designate familiarity (lecture slides versus instructor), we wanted to examine how similar the familiarity designations were depending on which of these two methods was used. To accomplish this, we compared the familiarity characterization for each exam question, and found that there were identical designations for at least fifty percent of the questions from each course examined (Figure 4). Of the remaining questions, the vast majority differed only by one level of familiarity, highlighting that while each designation method produced a unique perspective in terms of what was taught in a prerequisite course, there was considerable overlap between these perspectives. This is a similar conclusion as was seen in a previously published study (Shaffer et al. 2016).

\section{Impact of prior physiology laboratory on HA} performance.

Another context in which we wanted to examine the impact of prerequisites was a human anatomy course with a recommended human physiology laboratory course prerequisite. Many students who enrolled in the HA course successfully completed a human physiology laboratory course, one offered by either the Biological Sciences or Pharmaceutical Sciences departments. Since the anatomy covered in the human physiology laboratory courses overlap with material covered in the HA course, we hypothesized that students who successfully completed a human physiology laboratory course would earn significantly higher grades in $\mathrm{HA}$ than students who did not take the prerequisite course. When controlling for student GPA, students who successfully completed the Biological Sciences human physiology course (Bio PL) earned modest, but significant, higher final grades in the anatomy course (model estimate of $1.58+/-2.02$ out of 100 percent) than students who did not complete the prerequisite course (Table 3 ). This positive trend also existed for students enrolled in the other human physiology laboratory course (PharmSci PL) although the result was not statistically significant.

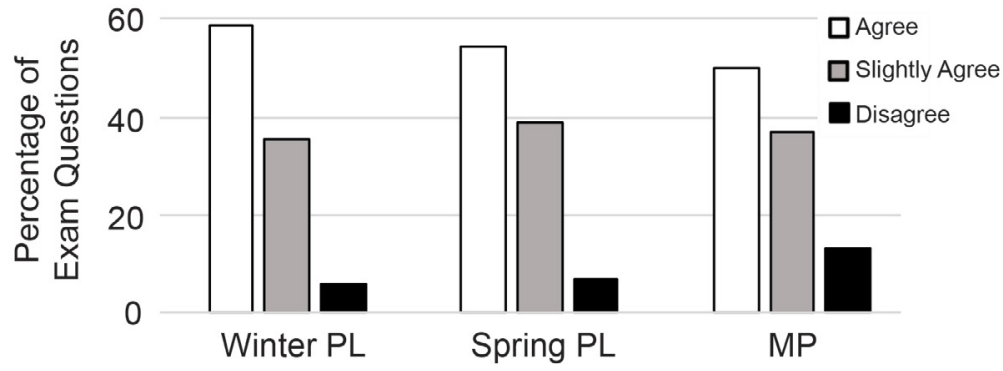

Figure 4. Comparison of instructor and slide familiarity characterization. Familiarity characterization of exam questions from the indicated course were compared according to whether they were designated by the instructor or lecture slides. Agree refers to ratings of a particular question that were identical between the two designation methods. Slightly agree refers to ratings that were off by one familiarity level. Disagree refers to ratings that were off by two familiarity levels.

Table 3. Student performance in human anatomy $(H A)$ based on prior physiology laboratory course completion

\begin{tabular}{|l|c|c|}
\hline & Final course grade & \\
\hline Regression coefficient & Estimate \pm SEM & $5.0 \mathrm{e}-15$ \\
\hline Model intercept & $29.09 \pm 3.56$ & 0.04 \\
\hline Lab (Bio PL) & $1.58 \pm 2.02$ & 0.58 \\
\hline Lab (PharmSci PL) & $0.78 \pm 1.42$ & $<2 \mathrm{e}-16$ \\
\hline GPA & $15.62 \pm 1.05$ & \\
\hline Adjusted R & 0.3726 & \\
\hline
\end{tabular}

The baseline for this model is students who did not successfully complete a human physiology laboratory course prior to enrolling in HA. Values for the estimates are provided as the mean +/- the standard error. 


\section{Discussion}

In this study, we investigated the potential impacts of a required prerequisite human physiology lecture course on a follow-up human physiology laboratory course and a follow-up molecular pharmacology course using the previously established familiarity categorization method. We also investigated the potential impact of a recommended prerequisite human physiology laboratory course on a followup human anatomy course by comparing exam performance between students who did and did not successfully complete the recommended prerequisite. Overall, we found limited evidence that the prerequisite courses played an important role in student success in the follow-up courses, which is contrary to our hypothesis (Figures 2 and 3). These results are similar to those previously reported for a human anatomy course and a human physiology prerequisite (Shaffer et al. 2016), a molecular biology course and a genetics prerequisite (Shaffer et al. 2016), and a microbiology laboratory course and a microbiology lecture prerequisite (Sato et al. 2017)

A possible reason that we did not find significantly higher achievement on very familiar questions could be that students have difficulty applying knowledge in a different context. Even though the courses in this study were closely linked in subject matter, students often have difficulties applying knowledge acquired in one situation to another, even when similar concepts are involved (Bransford et al. 2000). Another possibility is that students simply are not retaining what they learned in the prerequisite course. As knowledge may decay over time or due to interference from learning new information (Tomlinson et al. 2009, Bunce et al. 2011), it is possible that students initially learned the material in the prerequisite when the material was needed, but then lost that information over the time between the courses.

Conversely, the instructors of the subsequent courses may anticipate this, providing a sufficient review of previously covered material, making the prerequisite unnecessary. It is also possible that students may focus more on the new, unfamiliar, material and less on the prerequisite, familiar material, which could lead to a leveling of performance results. Finally, it may be possible that the prerequisite course and the follow-up courses were not well aligned with one another. Even though very familiar material was taught in the prerequisite course, the follow-up course may not have explicitly built on this material and thus inadvertently did not show the students how this material was related. As repetition and retrieval practice has been shown to improve learning (Roediger and Karpicke 2006a, Roediger and Karpicke 2006b, Karpicke and Blunt 2011, Dobson and Linderholm 2015), prerequisite courses could point out material that students will encounter in the follow-up course. Likewise, follow-up courses could explicitly show how the course builds on previous material.
In the case of recommended prerequisites, if the follow-up course builds on the prerequisite course, then it could be expected that students who have successfully completed the prerequisite course would earn higher grades in the followup course compared to students who did not complete the prerequisite course. In this study, we found limited support of this hypothesis. While students who completed a recommended prerequisite human physiology laboratory course earned significantly higher grades in a follow-up human anatomy course compared to students who did not enroll in the prerequisite, the effect was small (Table 3). This result is similar to those previously reported (Steele and Barnhill 1982, Canaday and Lancaster 1985, Wright et al. 2009, Sato et al. 2017).

While there is considerable overlap between a physiology laboratory course and a human anatomy course, the prerequisite physiology laboratory may not be important for success in the human anatomy course if the physiology laboratory course emphasizes physiology over anatomy. For example, a physiology laboratory course may emphasize electromyography, length-tension relationships, and the cross-bridge cycle in a unit on the muscular system, whereas a human anatomy course may emphasize muscle structure, location, identification, and nerve innervations. So, while the same organ systems were taught, they were done so with different goals, and thus the concepts covered in the physiology laboratory course may not directly impact student performance in the follow-up human anatomy courses.

\section{Limitations}

While our results largely show that the impact of prerequisite courses on student success in subsequent physiology courses is minimal, there are several limitations to this study. First, we assessed a limited number of course sequences at a single large research-intensive institution. The courses that were studied were designed relatively independently of one another, and as such there is room for improvement on the deliberate linkage between the courses. To this end, bigger impacts of prerequisites may be seen in physiology courses that are more tightly aligned with their prerequisite courses.

Additionally, the courses in this study assessed a single student population and results may differ if different populations are studied based on type of institution, geographic location, and ethnic/gender composition. The results of this study could also have been confounded by the fact that we did not conduct detailed written surveys or interviews with students, which could have revealed whether students had acquired knowledge of physiology in previous settings such as in other institutions or in high school. Finally, we only assessed the impact of prerequisite courses on a limited number of Core Concepts and physiology topics (see Methods). While it is possible that our results extend to other Core Concepts and topics, it is also possible that the impact of the prerequisite 
courses would have been larger for other areas. Future studies assessing a more thorough set of Core Concepts or physiology topics would be warranted to determine a broader impact of prerequisite courses on physiology education.

\section{Conclusion}

The results from this study highlight the importance of assessing course sequence and linkage during curricular design and reform since the results suggest that prerequisites may not be as critical for success as we thought (at least for the courses and students in this study).

We have two suggestions for increasing the alignment of courses for more positive outcomes. First, curriculum mapping could be used to identify common learning outcomes among prerequisite and follow-up courses (Uchiyama and Radin 2009), which could lead to improved linkage of theses courses and thus improved outcomes. Second, instructors of prerequisite and follow-up courses could meet regularly to discuss the content of both courses and how best to design the courses so that the follow-up courses build on the subject matter presented in the prerequisite courses.

As a central component of many health-related undergraduate and graduate programs, wide-scale exploration of the impact of physiology and anatomy and physiology courses would go a long way towards ensuring that we are providing a highquality educational experience for the next generation of health-care practitioners.

\section{Acknowledgements}

We would like to acknowledge and thank the students in our courses that took part in this study.

\section{About the Authors}

Justin Shaffer is a Teaching Associate Professor at the Colorado School of Mines. He teaches introductory biology and chemical engineering courses.

Sam Schriner is an Assistant Teaching Professor at UC Irvine where he teaches physiology.

Catherine Loudon is a Teaching Professor at UC Irvine where she teaches physiology.

Samantha Dacanay, Usman Alam, and Jennifer Dang earned their bachelor's degrees from UC Irvine.

Nancy Aguilar-Roca is an Associate Teaching Professor at UC Irvine where she teaches physiology.

Pavan Kadandale is an Associate Teaching Professor at UC Irvine where he teaches biochemistry.

Brian Sato is an Associate Teaching Professor at UC Irvine where he teaches molecular biology.

\section{Literature cited}

Bloom BS, Krathwohl DR, and Masia BB (1956) Taxonomy of educational objectives : the classification of educational goals. New York: D. McKay, p 2 volumes (207, xiv, 196 pages).

Bransford J, National Research Council (U.S.). Committee on Developments in the Science of Learning. and National Research Council (U.S.). Committee on Learning Research and Educational Practice (2000) How people learn : brain, mind, experience, and school. Washington, D.C.: National Academy Press, p x, 374 p.

Bunce DM, VandenPlas JR, Cameron S (2011) Decay of Student Knowledge in Chemistry. J Chem.I Educ. 88(9): 1231-1237.

Canaday SD and Lancaster CJ (1985) Impact of undergraduate courses on medical student performance in basic sciences. J Med Educ 60: 757-763.

Dobson JL and Linderholm T (2015) Self-testing promotes superior retention of anatomy and physiology information. Adv Health Sci Educ 20: 149-161. doi: 10.1007/ s10459-014-9514-8.

Forester JP, McWhorter DL, and Cole MS (2002) The relationship between premedical coursework in gross anatomy and histology and medical school performance in gross anatomy and histology. Clinical anatomy 15: 160-164. doi: 10.1002/ca.1114.

Heiner CE, Banet Al and Wieman C (2014) Preparing students for class: How to get $80 \%$ of students reading the textbook before class. Am J Phys 82: 989-996.

doi: 10.1119/1.4895008.

Karpicke JD and Blunt JR (2011) Retrieval Practice Produces More Learning than Elaborative Studying with Concept Mapping. Science 331: 772-775. doi: 10.1126/ science.1199327.

McCleary VL, Aasen G, and Slotnick HB (1999) Predictors of success in undergraduate human physiology. Am J Physiol 277: S119-126. doi: 10.1152/advances.1999.277.6.S119.

McRae MP (2010) Correlation of preadmission organic chemistry courses and academic performance in biochemistry at a midwest chiropractic doctoral program. J Chiropr Educ 24:30-34.

Michael J and McFarland J (2011) The core principles ("big ideas") of physiology: results of faculty surveys. Adv Physiol Educ 35: 336-341. doi: 10.1152/advan.00004.2011. 
Michael JA (1998) Students' misconceptions about perceived physiological responses. Am J Physiol 274: S90-98. doi: 10.1152/advances.1998.274.6.S90.

Michael JA, Richardson D, Rovick A, Modell H, Bruce D, Horwitz B, Hudson M, Silverthorn D, Whitescarver S, and Williams S (1999) Undergraduate students' misconceptions about respiratory physiology. Am J Physiol 277: S127-135. doi: 10.1152/advances.1999.277.6.S127.

Modell HI, Michael JA, Adamson T, Goldberg J, Horwitz BA, Bruce DS, Hudson ML, Whitescarver SA and Williams $S$ (2000) Helping undergraduates repair faulty mental models in the student laboratory. Adv Physiol Educ 23: 8290. doi: 10.1152/advances.2000.23.1.S82.

Richardson DR (2000) Comparison of naive and experienced students of elementary physiology on performance in an advanced course. Adv Physiol Educ 23: 91-95. doi: 10.1152/ advances.2000.23.1.S91.

Roediger HL and Karpicke JD (2006a) The Power of Testing Memory Basic Research and Implications for Educational Practice. Perspect Psychol Sci 1: 181-210.

doi: 10.1111/j.1745-6916.2006.00012.x.

Roediger HL and Karpicke JD (2006b) Test-enhanced learning - Taking memory tests improves long-term retention. Psychol Sci 17: 249-255. doi: DOI 10.1111/j.14679280.2006.01693.x.

Rovick AA, Michael JA, Modell HI, Bruce DS, Horwitz B, Adamson T, Richardson DR, Silverthorn DU, and Whitescarver SA (1999) How accurate are our assumptions about our students' background knowledge? Am J Physiol 276: S93-101. doi: 10.1152/advances.1999.276.6.S93.

Sato BK, Lee AK, Alam U, Dang JV, Dacanay SJ, Morgado P, Pirino G, Brunner JE, Castillo LA, Chan VW, and Sandholtz JH (2017) What's in a Prerequisite? A Mixed-Methods Approach to Identifying the Impact of a Prerequisite Course. CBE Life Sci Educ 16.

doi: 10.1187/cbe.16-08-0260.

Shaffer JF, Dang JV, Lee AK, Dacanay SJ, Alam U, Wong HY, Richards GJ, Kadandale P and Sato BK (2016) A Familiar(ity) Problem: Assessing the Impact of Prerequisites and Content Familiarity on Student Learning. Plos One 11: e0148051. doi: 10.1371/journal.pone.0148051.

Steele MW and Barnhill, BM (1982) Lack of impact of undergraduate genetic courses on the teaching of medical genetics. Am J Hum Genet 34: 501-506.
Tomlinson TD, Huber DE, Rieth CA, and Davelaar EJ (2009) An interference account of cue-independent forgetting in the no-think paradigm. Proceedings of the National Academy of Sciences of the United States of America 106: 15588-15593. doi: 10.1073/pnas.0813370106.

Uchiyama KP and Radin JL (2009) Curriculum Mapping in Higher Education: A Vehicle for Collaboration. Innovative Higher Education 33:271-280.

Wright R, Cotner S, and Winkel A (2009) Minimal impact of organic chemistry prerequisite on student performance in introductory biochemistry. CBE Life Sci Educ 8: 44-54. doi: 10.1187/cbe.07-10-0093.

Welsh AJ (2012) Exploring undergraduates' perceptions of the use of active learning techniques in science lectures. $J$ Coll Sci Teach 42: 80-87. 